\title{
LAURENCE-MOON-BIEDL SYNDROME (LMBS) - A RARE AUTOSOMAL RECESSIVE SYNDROME - WITH RETINITIS PIGMENTOSA - A CASE REPORT
}

Naushad Ali N. Malagi ${ }^{1}$, Mohamad Rafiq Ustad ${ }^{2}$, Sadashiv B. Ukkali³ ${ }^{3}$ Faisal Farooqui ${ }^{4}$

\section{HOW TO CITE THIS ARTICLE:}

Naushad Ali N. Malagi, Mohamad Rafiq Ustad, Sadashiv B. Ukkali, Faisal Farooqui. "Laurence-moon-biedl syndrome (LMBS) - A Rare Autosomal Recessive syndrome - with retinitis pigmentosa - a case report". Journal of Evolution of Medical and Dental Sciences 2013; Vol2, Issue 31, August 5; Page: 5713 - 5716.

ABSTRACT: Laurence-Moon-Bardet-Biedl syndrome is a rare, genetically heterogeneous, autosomal recessive inherited disorder with wide variability in expression. We report a case of Laurence-MoonBardet-Biedl syndrome. The diagnosis had been missed until the patient presented at our hospital.

KEY-WORDS: Laurence-moon- biedl syndrome, obesity, polydactyly, retinitis pigmentosa.

INTRODUCTION: Laurence-Moon-Bardet-Biedl syndrome (LMBBS) is a rare, genetically heterogeneous, autosomal recessive disorder characterized by early onset retinitis pigmentosa, post axial polydactyly, central obesity, mental retardation, hypogonadism and kidney structural abnormalities or functional impairment. We report here a typical case of Laurence-Moon-BardetBiedl syndrome in a five-year old boy. We also present a review of the diagnosis and management of interesting syndrome.

CASE REPORT: A five year boy was brought to the Pediatric OPD of our hospital with complaint of excessive weight gain noticed since early childhood. He was born out of $3^{\text {rd }}$ degree consanguineous marriage of a 29 year-old mother and 34 year old father. He was born at term, with no antenatal or perinatal complications, with all other family members being normal. He had progressive deterioration in vision for the last 3 years, starting with difficulty in seeing at night.

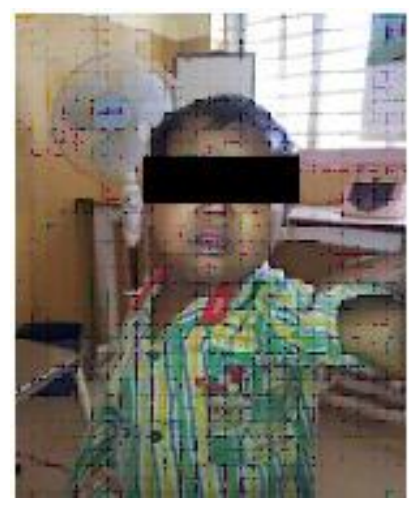

There was history of development delay also. He had consulted many pediatricians and ophthalmologists for his condition but remained undiagnosed and presented to our hospital. On examination, he was markedly obese. His weight was 19kg; height was $102 \mathrm{~cm}$. His blood pressure was 118/70 mm Hg. There was postaxial polydactyly of right lower limb. Examination of the external genitalia revealed stretched penile length $2 \mathrm{~cm}$ (microphallus) and testicular volume of $2 \mathrm{ml}$ bilaterally. Ophthalmologic examination revealed visual acuity of 1/60 (right) and 2/60 (left). 
Fundus showed a waxy pale disc with marked attenuation of arterioles and pigment clumps at the periphery suggestive of retinitis pigmentosa. His IQ was 40.

The fasting blood glucose was $84 \mathrm{mg} \%$. Renal function tests were normal. Liver function tests showed elevated enzymes with an SGOT of 83 IU and SGPT of 132 IU. Viral markers for hepatitis $\mathrm{B}$ and $\mathrm{C}$ were negative. The lipid profile was as follows: Total cholesterol $173 \mathrm{mg} \%$, H.D.L.: $41 \mathrm{mg} \%$, V.L.D.L.: $23 \mathrm{mg} \%$, L.D.L.: $109 \mathrm{mg} \%$, Triglycerides $117 \mathrm{mg} \%$; all of which are within normal limits. His hormone profile was FSH $3.31 \mathrm{miu} / \mathrm{ml}$ (normal1-8), LH $0.30 \mathrm{miu} / \mathrm{ml}$ (normal 2-12), Testosterone $0.12 \mathrm{nmol} / \mathrm{l}$ (normal 8.71-36.47), TSH $3.77 \mathrm{micro}$ IU/ ml (normal 0.49-4.67). Urine examination revealed +1 proteinuria. A 24 -h urinary collection revealed $0.2 \mathrm{~g}$ of protein. A diagnosis of Laurence-Moon-Bardet-Biedl syndrome having central obesity, postaxial polydactyly, mental retardation, retinitis pigmentosa, hypogonadism and functional renal impairment was made followed up for pubertal development for the next few years as hypogonadism is a likely problem.

DISCUSSION: The patient above is a classical case of Laurence- Moon-Bardet-Biedl syndrome.

The syndrome was independently described by Bardet and Biedl in the 1920s. There was controversy in medical literature with the condition described in 1865 by Laurence and Moon, referred as Laurence and Moon syndrome (LMS). After a 22-year prospective cohort study of 46 patients from 26 Newfoundland families with BBS, Moore et al concluded that BBS and LMS are different spectrum of same entity. The variable manifestations of this syndrome can be explained on molecular basis by ciliopathy.

The condition was thought to be rare, but this may have been due to the failure to diagnose incomplete or partial cases. The prevalence of LMBS is 1: 160,000 in Europe. However, its prevalence is markedly increased in highly consanguineous Arab-Bedouin communities in the Arab population of Kuwait (1: 13 500).

Recent advances in genetics have enabled investigators to define syndromes by specific mutations. Eleven genes are known to be associated with this syndrome: BBS1, BBS2, ARL6/BBS3, BBS4, BBS5, MKKS/BBS6, BBS7, TTC8/BBS8, B1/BBS9, BBS10, and TRIM32/ BBS11.4. The syndrome is transmitted as an autosomal recessive trait. There is considerable heterogeneity and intra-familial variation in the extent and severity of clinical manifestations of LMBBS. The diagnosis of LMBBS is established by clinical criteria.

\section{REFERENCES:}

1. Schachat A P, Maumenee IH. The Bardet-Biedl syndrome and related disorders. Arch Ophthal 1982; 100:285-8.

2. Moore SJ, Green J S, Fan Y, Bhogal AK, Dicks E, Fernandez BA, et al. Clinical and genetic epidemiology of Bardet- Biedl syndrome in Newfoundland: a 22-year prospective, population-based, cohort study. Am J Med Genet 2005; 132:352- 60?

3. Woods MO, Young T L, Parfrey PS, Hefferton D, Green J S, Davidson WS. Genetic heterogeneity of Bardet-Biedl syndrome in a distinct Canadian population: evidence for a fifth locus. Genomics 1999; 55:2-9.

4. Beales P L, Elcioglu N, Woolf A S, Parker D, Flinter F A. New criteria for improved diagnosis of Bardet-Biedl syndrome: results of a population survey. J Med Genet 1999; 36(6):437- 46. 


\section{CASE REPORT}

5. O'Dea D, Parfrey PS, Harnett JD, Hefferton D, Cramer BC, Green J. The importance of renal impairment in the natural history of Bardet-Biedl syndrome. Am J Kidney Dis 1996; 27(6):776-83.
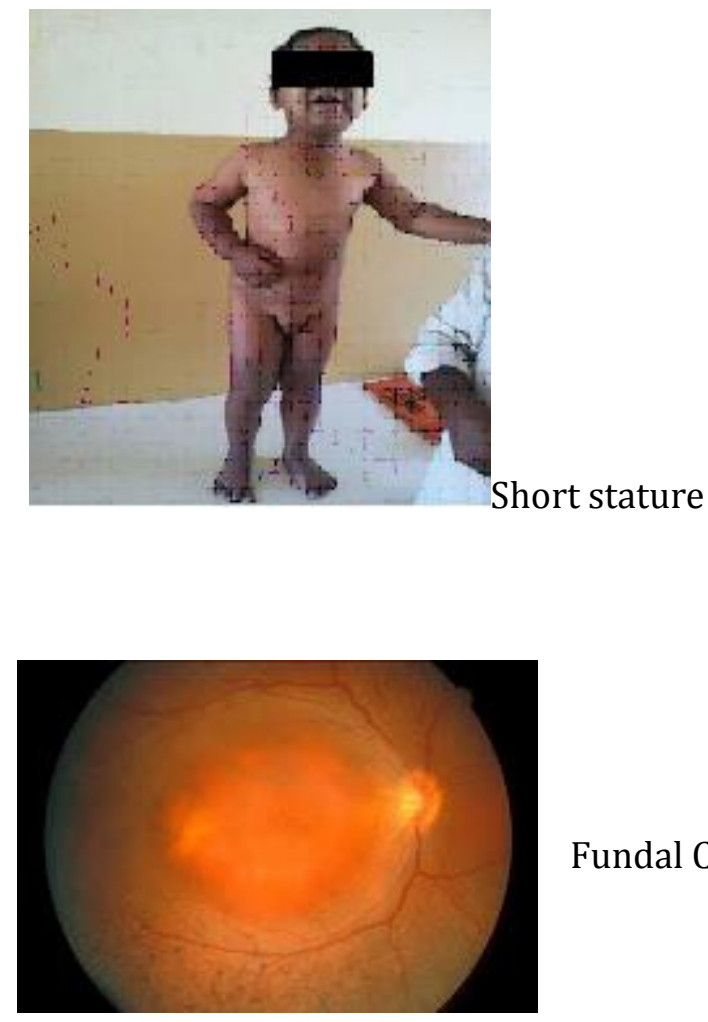

Fundal Changes

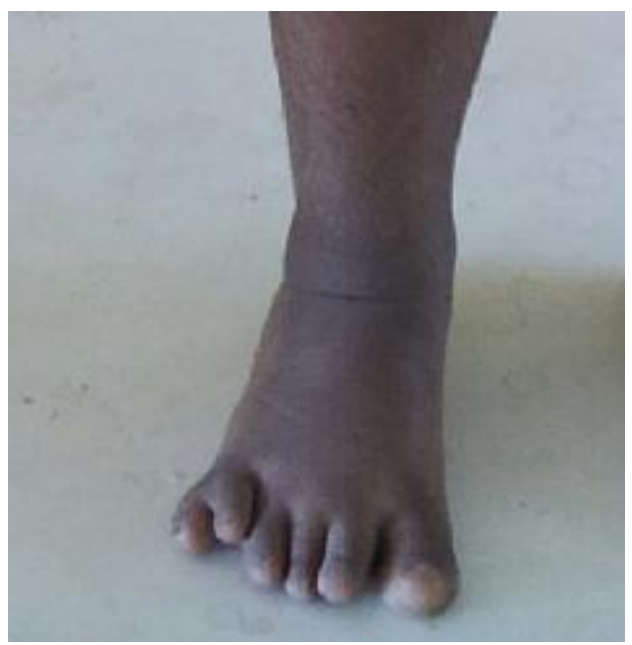

Polydactyly 


\section{CASE REPORT}

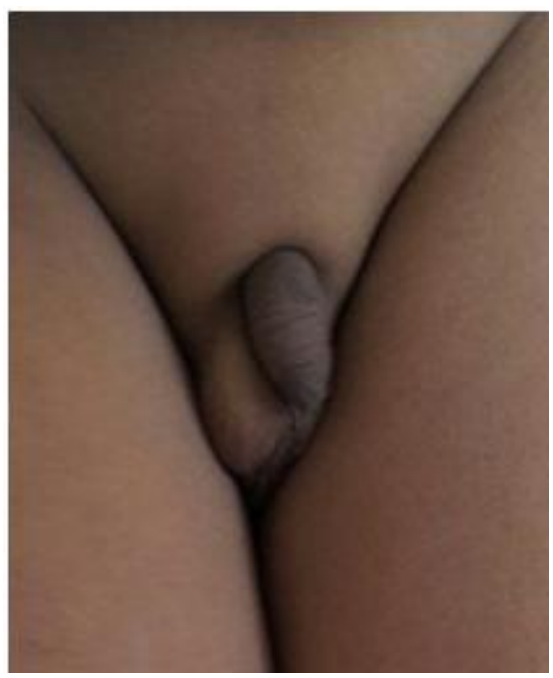

Microphallus

\section{AUTHORS:}

1. Naushad Ali N. Malagi

2. Md. Rafiq Ustad

3. Sadashiv B. Ukkali

4. Faisal Farooqui

\section{PARTICULARS OF CONTRIBUTORS:}

1. Associate Professor, Department of Pediatrics, AlAmeen Medical College, Bijapur.

2. Second Year MD-PG, Department of Pediatrics, AlAmeen Medical College, Bijapur.

3. Assistant Professor, Department of Pediatrics, AlAmeen Medical College, Bijapur.

4. Senior Resident, Department of Pediatrics, AlAmeen Medical College, Bijapur.

\section{NAME ADRRESS EMAIL ID OF THE} CORRESPONDING AUTHOR:

Dr. Naushad Ali N. Malagi, Kausar Manzil, Nehru Nagar, Behind KSRTC Depot, Bijapur - 586101, Karnataka, India.

Email: drnaushadmalagi@gmail.com

Date of Submission: 20/07/2013. Date of Peer Review: 22/07/2013. Date of Acceptance: 23/07/2013. Date of Publishing: 30/07/2013 